\title{
The Economic Value of Wind Energy Nowcasting
}

\author{
Aurore Dupré ${ }^{1, *,+} \oplus$, Philippe Drobinski ${ }^{1}$, Jordi Badosa ${ }^{1}$, Christian Briard ${ }^{2}$ and Peter Tankov ${ }^{3, *}$ \\ 1 LMD/IPSL, École Polytechnique, Institut Polytechnique de Paris, ENS, PSL, Research University, \\ Sorbonne Université, CNRS, 91120 Palaiseau, France; philippe.drobinski@lmd.polytechnique.fr (P.D.); \\ jordi.badosa@lmd.polytechnique.fr (J.B.) \\ 2 Zephyr ENR, 37550 Saint-Avertin, France; ch.briard@zephyr-enr.fr \\ 3 CREST, ENSAE, Institut polytechnique de Paris, 91120 Palaiseau, France \\ * Correspondence: aurore.dupre@inria.fr (A.D.); peter.tankov@polytechnique.org (P.T.) \\ † Current address: Inria Sophia-Antipolis Méditerrannée, 2004 Route des Lucioles, 06902 Valbonne, France.
}

Received: 31 July 2020; Accepted: 28 September 2020; Published: 10 October 2020

\begin{abstract}
In recent years, environmental concerns resulted in an increase in the use of renewable resources such as wind energy. However, high penetration of the wind power is a challenge due to the intermittency of this resource. In this context, the wind energy forecasting has become a major issue. In particular, for the end users of wind energy forecasts, a critical but often neglected issue is the economic value of the forecast. In this work, we investigate the economic value of forecasting from $30 \mathrm{~min}$ to $3 \mathrm{~h}$ ahead, also known as nowcasting. Nowcasting is mainly used to inform trading decisions in the intraday market. Two sources of uncertainty affecting wind farm revenues are investigated, namely forecasting errors and price variations. The impact of these uncertainties is assessed for six wind farms and several balancing strategies using market data. Results are compared with the baseline case of no nowcasting and with the idealized case of perfect nowcast. The three settings show significant differences while the impact of the choice of a specific balancing strategy appears minor.
\end{abstract}

Keywords: wind energy forecasting; nowcasting; electricity market; balancing strategies

\section{Introduction}

Intermittent renewable sources such as wind energy are subject to rapid and unpredictable changes. In this context, if producers are part of a liberalized electricity market, they are exposed to penalties related to the costs of regulating the grid.

The centerpiece of modern electricity markets is the day-ahead, or spot market, where most electricity purchases and sales take place. The day-ahead market is a one-off auction where producers and consumers submit their bids and offers before 12:00 for each hour of following day, and the price for each hour is determined by balancing supply and demand. Thus, offers are made between 12 and $35 \mathrm{~h}$ before the delivery. Following the announcement of the day-ahead prices, the intraday market opens, allowing the participants to adjust their positions taken in the day-ahead market as new information becomes available. The intraday market is a continuous trading venue, similar to a stock trading platform, where bids and offers for delivery hours, half-hours or quarter-hours of the next day are placed in the order book, and matching bids/offers are executed immediately, resulting in a transaction. The electricity market opens at 15:00 on the previous day and the trading continues until 5 to $30 \mathrm{~min}$ before delivery for each unit, but significant liquidity usually only becomes available 5 to $6 \mathrm{~h}$ before delivery.

On delivery, producers are charged for any negative imbalance, defined as the difference between real production and the aggregate market position (day-ahead plus intraday). Positive imbalances give rise to payments. However, the corresponding imbalance prices may be lower than the market prices 
that the producer would have obtained in the day-ahead or intraday market. The actual balancing prices are computed post-factum, depending on the costs of the grid regulation [1].

Several studies showed that accurate forecasts can be used to enhance the value of wind energy production. Roulston et al. [2] compared the use of forecast from the European Centre for Medium-Range Weather Forecasts (ECMWF) for 1 to 10 days lead time, and the climatology to bid in the day-ahead market in the UK. They find that with forecasts based on ECMWF, the daily income is higher on $60 \%$ of the days compared with climatology. Moreover, the weekly income is higher on $80 \%$ of the weeks. Pinson et al. [3] showed that one way to define sophisticated strategies to participate in the Danish day-ahead market is to provide, in addition to forecasts, information about their uncertainty. Barthelmie et al. [4] studied the use of forecasts up to $36 \mathrm{~h}$ lead time for trading in the day-ahead market and show that a perfect forecast leads to a price advantage of about $4.5 £$ per MWh. As in [2], their study is based on the UK market. Fabbri et al. [5] assessed the costs of forecasting errors for wind energy producers bidding in the Spanish day-ahead and intraday market. Considering three case studies (one wind farm, 15 wind farms and the total Spanish production), they show that these costs can reach as much as $10 \%$ of the total generator energy income. Usaola et al. [6] showed that revenues can be increased with an hourly wind energy forecast from $1 \mathrm{~h}$ to $48 \mathrm{~h}$ lead-time, based on in situ measurements and numercial weather prediction (NWP) model outputs, and used to bid on the day-ahead and intraday markets. Using the rules of the Spanish electricity market, they show that with such a forecast, the income is reduced by $7.5 \%$ with respect to perfect forecast due to forecasting error. Its is reduced by $9.5 \%$ when persistence is used and $10 \%$ when no forecast is used. Matevosyan et al. [7] described a method to simulate the Nordic power market (Norway, Finland, Sweden, and Denmark). It is based on imbalance price to minimize imbalance costs. They combine this model with wind energy forecasts from $18 \mathrm{~h}$ to $41 \mathrm{~h}$ lead time, to build a stochastic optimization model in order to generate optimal wind power production bids for the day-ahead market.

An economic quantification of the value of the forecast is a way of assessing its performance for users who are more interested in maximizing revenue from the use of the forecast than in the forecast itself.

Most of the studies mentioned above focus on wind energy forecasting in order to sell energy on the day-ahead market. However, the added value of nowcasting, to bid on the intraday market, is rarely investigated. The goal of this paper is therefore to quantify the economic value of nowcasting for a producer with a lead time ranging from $30 \mathrm{~min}$ to $3 \mathrm{~h}$. We focus on the value of nowcasting for balancing wind production in the intraday market, to minimize the imbalance penalties. Our tests are conducted using the data from six specific wind farms situated at different locations in France; two of these farms are analyzed in more detail. We use the French electricity market rules and data from EPEX Spot.

After the introduction, the methodology is described in Section 2, with the overview of the data sets (in situ measurements, NWP outputs and price data), the details of the nowcasting model used in the study and the description of the French electricity market. In Section 3, the two sources of uncertainty faced by the wind producer are discussed. They include the forecasting model uncertainty, which is expected to decrease with shorter lead times, and on the other hand, the market price volatility, which is expected to increase with shorter lead times. To identify the impact of the uncertainties on the revenues of producers, Section 4 compares various scenarios: the case where no nowcast is available, the case where a perfect nowcast is available, and the case where a realistic nowcast is available. The impact of these three scenarios is analyzed in depth with respect to the contribution of the two sources of variability. Finally, one-year income obtained using several nowcasts is compared at six existing wind farms. Section 5 discusses the results, summarizes the main outcome and provides perspectives.

It is essential to mention that in practice, small wind producers cannot access the market directly, but sell their energy through an aggregator. This being said, the methodology of this study remains 
valid, it would simply be necessary to transpose it to the aggregator scale, and only the numbers presented would vary.

\section{Methodology}

\subsection{Data Sets}

Several data sets are needed for this study. For the wind and wind energy production, we use in situ measurements from the company Zephyr ENR. Zephyr ENR is a French company owner of 6 wind farms in North-Western France (see Figure 1). For each wind farm, the characteristics of the site and the wind turbines are listed in Table 1.

Table 1. Main characteristics of the 6 considered wind farm including: the location, the commissioning year, the number, type and reference of the wind turbines and the hub height.

\begin{tabular}{ccccc}
\hline Name & Location & $\begin{array}{c}\text { Commissioning } \\
\text { Year }\end{array}$ & $\begin{array}{c}\text { Number, Type and } \\
\text { Reference of Turbines }\end{array}$ & $\begin{array}{c}\text { Hub } \\
\text { Height }\end{array}$ \\
\hline Parc de Bonneval (A) & $\left(48.20^{\circ} \mathrm{N}, 1.42^{\circ} \mathrm{E}\right)$ & 2006 & 6 Vestas V80-2 MW & $100 \mathrm{~m}$ \\
Moulin de Pierre (B) & $\left(48.24^{\circ} \mathrm{N}, 1.47^{\circ} \mathrm{E}\right)$ & 2017 & 6 Vestas V112-3 MW & $94 \mathrm{~m}$ \\
Parc de Beaumont (C) & $\left(47.60^{\circ} \mathrm{N}, 1.44^{\circ} \mathrm{W}\right)$ & 2015 & 6 Vestas V100-2 MW & $95 \mathrm{~m}$ \\
Parc de la Renardière (D) & $\left(47.64^{\circ} \mathrm{N}, 1.48^{\circ} \mathrm{W}\right)$ & 2009 & 6 Senvion MM92-2 MW & $100 \mathrm{~m}$ \\
Parc de la Haute Chèvre (E) & $\left(49.04^{\circ} \mathrm{N}, 0.93^{\circ} \mathrm{W}\right)$ & 2011 & 3 Enercon E82-2.3 MW & $85 \mathrm{~m}$ \\
Parc de la Vènerie (F) & $\left(49.01^{\circ} \mathrm{N}, 1.16^{\circ} \mathrm{W}\right)$ & 2014 & 4 Enercon E82-2.3 MW & $85 \mathrm{~m}$ \\
\hline
\end{tabular}

This study was conducted in the six wind farms with similar results. Consequently the two most representative farms are investigated in-depth for illustration: Parc de Bonneval and Parc de la Vènerie (in red in Figure 1). Parc de Bonneval is located in the fields with a flat topography, while Parc de la Vènerie is surrounded by forests with a more rugged topography. Several measurements are collected at the hub height. The wind speed is measured with a sampling period of $1 \mathrm{~s}$ with anemometers located on the nacelle, behind the blades. Then, $10 \mathrm{~min}$ averages are retrieved for both wind speed and wind energy. In this study, this 10 min data for the year 2015 are used.

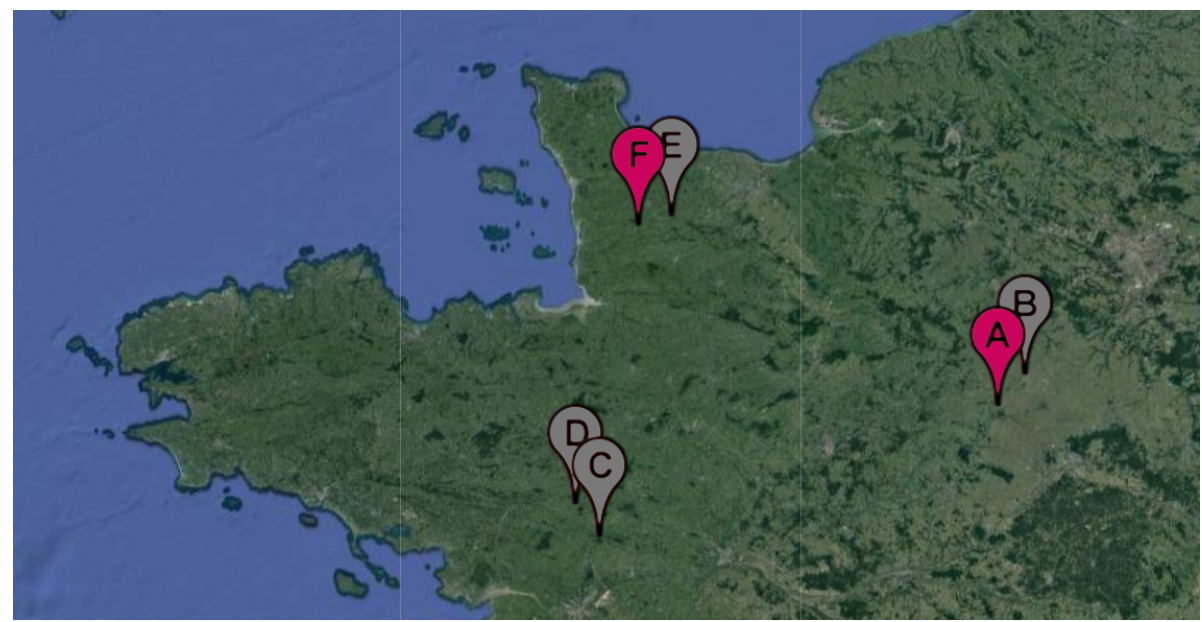

Figure 1. Location of the wind farms owned by Zephyr ENR. There are Parc de Bonneval (A), Moulin de Pierre (B), Parc de Beaumont (C), Parc de la Renardière (D), Parc de la Haute Chèvre (E), and Parc de la Vènerie (F). In this study, results are shown for the two wind farms in red: Parc de Bonneval and Parc de la Vènerie. Figure extracted from Google Earth.

Electricity market price data for this study were obtained from Epex Spot, the electricity exchange managing the day-ahead electricity markets of France, Germany, Austria and Switzerland. We use the hourly day-ahead prices, the last intraday prices, and, for the detailed analysis of the two representative 
wind farms, the German order book data. All prices were retrieved for the year 2015. The order book dataset contains all orders submitted to the intraday market from the time the intraday market opens until the market closes. We apply the algorithm by Martin et al. [8] to simulate the limit order book (LOB) and reconstruct the bid and offer prices.

The balancing penalties computed by the French transmission system operator RTE (Réseau de Transport d'Électricité), depending on grid regulation costs (https:/ / clients.rte-france.com/lang/an/ visiteurs/vie/mecanisme/volumes_prix/pre.jsp), were retrieved from RTE website for the year 2015 .

\subsection{Forecasting Models}

For the market simulations in this study, two forecasting models are used.

To determine the positions to take in the day-ahead market, wind energy production forecasts from $12 \mathrm{~h}$ ahead to $35 \mathrm{~h}$ ahead are needed. To this end, we use the hourly forecasts of the wind speed up to 4 days from the European Centre for Medium-Range Weather Forecasts (ECMWF). The spatial resolution of ECMWF forecasts is of about $16 \mathrm{~km}\left(0.125^{\circ}\right.$ in latitude and longitude). The wind speed is forecasted at $100 \mathrm{~m}$ which is the hub height at Parc de Bonneval. At Parc de la Vènerie, where the turbine height is $85 \mathrm{~m}$, so height correction is needed to avoid overestimation. The wind speed at $85 \mathrm{~m}$ is inferred from the $10 \mathrm{~m}$ and $100 \mathrm{~m}$ wind speed forecasts using the power law given by:

$$
U_{z}=c z^{\alpha}
$$

where $U_{z}$ is the wind speed at altitude $z$ and $c$ and $\alpha$ are parameters to be estimated. Using the data from 2015, $\alpha$ can be easily computed using Equation (1):

$$
\hat{\alpha}=\frac{\log \left(\overline{U_{10}}\right)-\log \left(\overline{U_{100}}\right)}{\log (10)-\log (100)},
$$

where $\overline{U_{10}}$ and $\overline{U_{100}}$ are $10 \mathrm{~m}$ and $100 \mathrm{~m}$ wind speed from ECMWF averaged over 2015. The interpolated wind speed at $85 \mathrm{~m}$ height is then given by:

$$
\widehat{U}_{85}=U_{100}\left(\frac{85}{100}\right)^{\hat{\alpha}}
$$

To compute the wind energy forecasts we used the power curve of the turbines. We model the power curves according to the standard methodology of The Standard International IEC 61400-12-1 [9]. The methodology consists of modeling the power curve by dividing the wind speed dataset onto $0.5 \mathrm{~m} \mathrm{~s}^{-1}$ intervals. For each wind speed intervals we compute the corresponding averaged power. Then the computed power curve is retrieved by fitting these means.

To determine positions to take in the intraday market, nowcasts are needed. In this study we focus on nowcasts from $30 \mathrm{~min}$ ahead (for the transactions taking place just before intraday market closure) to $3 \mathrm{~h}$ ahead. To this end, we use the nowcasting model described in [10], which will be referred herefater to as $\mathrm{LR}_{\mathrm{SW}}^{\mathrm{obs}}$ (see the Notations list). It is a downscaling model with low cost assimilation, which uses ECMWF forecasts and in situ measurements as explanatory variables.

The explanatory variables are listed in Table 2 . These include variables representative of the large scale weather systems (wind speed at altitude, vorticity, ...) as well as mean and turbulence surface variables characterizing the stability of the boundary layer meteorology (e.g., typically the first 1-km deep layer of the atmosphre). To this set of variables, is added the error between the wind speed measured at time $t_{0}$, time at which the nowcast is initiated, and the ECMWF forecasted wind speed at lead time $t$, i.e., $V_{t_{0}}^{\text {hub_height }}-V_{t_{0}}^{\mathrm{ECMWF}}(t)$. 
Table 2. Explanatory variables from ECMWF forecasts used as input of the nowcast model LR $\mathrm{SW}_{\mathrm{SW}}^{\mathrm{obs}}$.

(a) Surface variables

\begin{tabular}{ccc}
\hline Altitude $(\mathbf{m})$ & Variable & Unit \\
\hline \multirow{2}{*}{$10 \mathrm{~m} / 100 \mathrm{~m}$} & Zonal wind speed & $\mathrm{m} \mathrm{s}^{-1}$ \\
& Meridional wind speed & $\mathrm{m} \mathrm{s}^{-1}$ \\
& Temperature & $\mathrm{K}$ \\
& Dew point temperature & $\mathrm{K}$ \\
& Skin temperature & $\mathrm{K}$ \\
Surface & Mean sea level pressure & $\mathrm{Pa}$ \\
& Surface pressure & $\mathrm{Pa}$ \\
& Surface latent heat flux & $\mathrm{J} \mathrm{m}^{-2}$ \\
& Surface sensible heat flux & $\mathrm{J} \mathrm{m}^{-2}$ \\
& Boundary layer dissipation & $\mathrm{J} \mathrm{m}^{-2}$ \\
& Boundary layer height & $\mathrm{m}^{-}$ \\
\hline
\end{tabular}

(b) Altitude variables

\begin{tabular}{ccc}
\hline Pressure Level (hPa) & Variable & Unit \\
\hline & Zonal wind speed & $\mathrm{m} \mathrm{s}^{-1}$ \\
$1000 \mathrm{hPa} / 925 \mathrm{hPa} /$ & Meridional wind speed & $\mathrm{m} \mathrm{s}^{-1}$ \\
$850 \mathrm{hPa} / 700 \mathrm{hPa} /$ & Geopotential height & $\mathrm{m}^{2} \mathrm{~s}^{-2}$ \\
$500 \mathrm{hPa}$ & Divergence & $\mathrm{s}^{-1}$ \\
& Vorticity & $\mathrm{s}^{-1}$ \\
& Temperature & $\mathrm{K}$ \\
\hline & (c) Computed variables & \\
\hline Altitude & Variable & Unit \\
\hline $10 \mathrm{~m} / 100 \mathrm{~m}$ & Norm of the wind speed & $\mathrm{m} \mathrm{s}^{-1}$ \\
Between $10 \mathrm{~m}$ & Wind shear & $\mathrm{m} \mathrm{s}^{-1}$ \\
and $925 \mathrm{hPa}$ & Temperature gradient & $\mathrm{K}$ \\
\hline
\end{tabular}

Among the explanatory variables, some can be correlated and some other probably provide important information. To limit the number of explanatory variable and limit the overfitting by keeping the important and uncorrelated variables, a forward selection is performed. This iterative procedure, adds variables from the set of explanatory variables based on a choosen criteria. In this case, we choose the Bayesian Inference Criterion (BIC) [11] which is based on the likelihood function. The forward selection introduce a penalty term related to the number of parameter in the model, in order to reduce the overfitting. The model with the lowest BIC is preferred. At each step, the explanatory variable which minimize the BIC of the resulting model, is added. The procedure is repeated as long as the BIC decreases.

Dupré et al. [10] show that this model overperforms the classical benchmark models, such as Artificial Neural Networks [12], or Auto Regressive Moving Average models [13] for nowcasting applications (i.e., from $10 \mathrm{~min}$ to $3 \mathrm{~h}$ ). In [10], the authors also consider a downscaling model without assimilation of observations: $\mathrm{LR}_{\mathrm{SW}}^{\text {no-obs }}$ (see the Notation list). This model will be used in the following in a benchmark comparing $\mathrm{LR}_{\mathrm{SW}}^{\mathrm{obs}}, \mathrm{LR}_{\mathrm{SW}}^{\mathrm{no}}$,obs, $\mathrm{ECMWF}$ forecasts and persistence.

\subsection{Electricity Market}

The short-term electricity trading in France and most other European countries is organized in three stages, shown in Figure 2 for a given delivery date $t_{0}$ [1].

The day-ahead market, where most short-term trading takes place, is a one-off auction where participants submit bids for specific delivery hours, or blocks of hours, of the following day, and prices are determined by supply and demand. The bids for the next day must be submitted before 12:00. In our simulation, the producer is assumed to make bids based on wind energy forecasts computed from ECWMF wind forecasts as explained above. Since the forecast starting at 1200 UTC (Universal Time 
Coordinate) with French local time being UTC $+1 \mathrm{~h}$ in winter and UTC $+2 \mathrm{~h}$ in summer), the forecast is not yet available to determine the bid to be submitted before 12:00, so the forecast starting at 0000 UTC is used instead. This results in using forecasts with horizons from $24 \mathrm{~h}$ to $47 \mathrm{~h}$ for day-ahead bidding.

After making the initial transaction in the day-ahead market, the producer has the possibility to adjust the position in the intraday market if the production forecast has changed. The intraday market opens at 15:00 on the day preceding delivery, and transactions are possible until 5 to $30 \mathrm{~min}$ before the delivery time (depending on the product). It operates continuously as an order book where market participants may place orders.

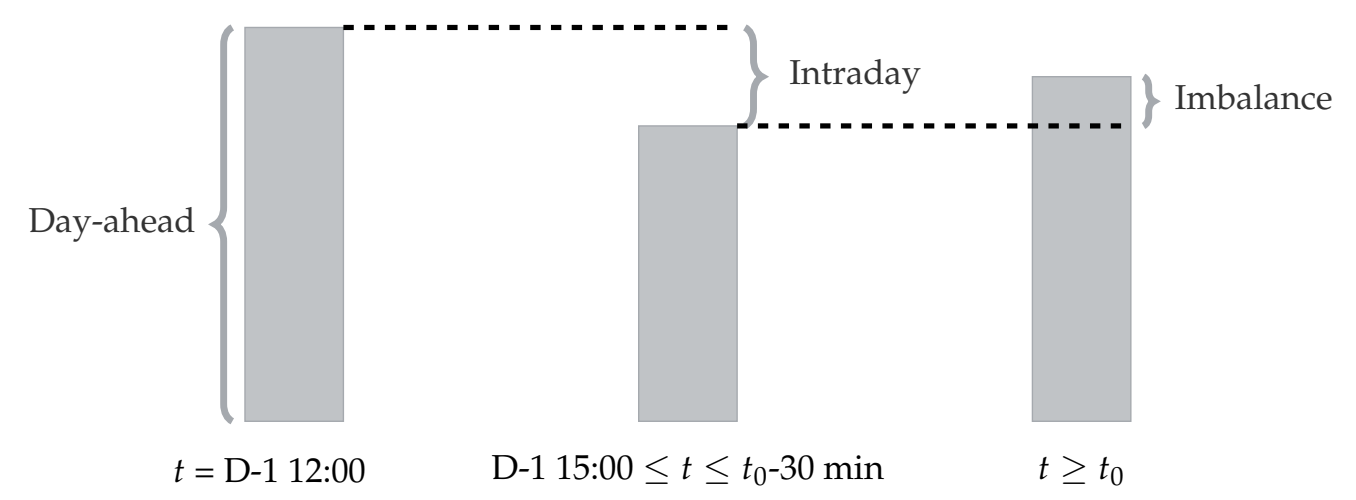

Forecasts from: $\quad$ ECMWF $\quad \mathrm{LR}_{\mathrm{SW}}^{\mathrm{obs}}$

Figure 2. Electricity market organization for delivery at time $t_{0}$. The day-ahead market operates as a one-time auction at 12:00 on the day before the delivery date, for each slot of the next day. The intraday market opens at 15:00 on the day before delivery and operates continuously until 5 to 30 min before the delivery time. Upon delivery, RTE compensates any imbalances using the imbalance market and issues appropriate imbalance payments/collects imbalance penalties from market participants.

It should be emphasized that although it is possible to trade in the intraday market starting from 15:00 on the day before delivery (that is, for example, $32 \mathrm{~h}$ before delivery for the last slot of the delivery day), most transactions take place a few hours ( $4-5 \mathrm{~h}$ ) before delivery time [14]. In our simulations we therefore assume that producers use nowcasts to adjust their positions in the intraday market $3 \mathrm{~h}$ to $30 \mathrm{~min}$ before delivery. It is a priori more advantageous to sell the production in the day-ahead market if it can be well forecasted, because the day-ahead market is more liquid. On the other hand, balancing the production in the intraday market at the last moment can be tempting as the forecasts are as accurate as possible. However, price volatility increases significantly as the delivery date approaches [14], so it is more risky to wait.

Finally, any differences between the the electricity produced and the electricity sold are compensated financially by RTE using the imbalance settlement prices. These prices are set according to the cost of additional generating units RTE must call upon to balance the French electricity system. At this point there are two possibilities: whether the producer has delivered too much electricity and is forced to refund the difference at a generally lower price than in the intraday market. Or he has delivered a lower amount of electricity and is forced to buy the difference at a generally higher price than in the intraday market.

Using the nowcasts and the different market prices, the total income from electricity generated during delivery hour $t, I_{t}^{\text {tot }}$ can be calculated as the sum of the incomes from each stage of the market:

$$
I_{t}^{\text {tot }}=I_{t}^{\text {day-ahead }}+I_{t}^{\text {intraday }}+I_{t}^{\text {imbalance }},
$$


where $I_{t}^{\text {day-ahead }}$ is the income from the day-ahead market, $I_{t}^{\text {intraday }}$ is the income from the intraday market and $I_{t}^{\text {imbalance }}$ is the income from imbalance settlement (see the Notation list). The three sources of income are defined as follows:

$$
\left\{\begin{array}{l}
I_{t}^{\text {day-ahead }}=F_{t}^{\mathrm{ECMWF}} \times p_{t}^{\text {day-ahead }} \\
I_{t}^{\text {intraday }}=\left(F_{t}^{\mathrm{LR} \mathrm{R}_{\mathrm{SW}}^{\mathrm{obs}}}-F_{t}^{\mathrm{ECMWF}}\right) \times p_{t}^{\text {intraday }} \\
I_{t}^{\text {imbalance }}=\left(F_{t}^{\text {real }}-F_{t}^{\mathrm{LR}}\right) \times p_{t}^{\text {ibs }} \text { ibalance }
\end{array}\right.
$$

where $F_{t}^{\mathrm{ECMWF}}$ is the forecast of the energy production (in MWh) computed from the ECMWF wind speed forecast, $F_{t}^{\mathrm{LR} R_{S W}^{\mathrm{obs}}}$ is the nowcast of the wind energy production, $F_{t}^{\text {real }}$ is the actual energy production; $p_{t}^{\text {day-ahead }}$ is the price at which energy was sold in the day-ahead market, $p_{t}^{\text {intraday }}$ is the

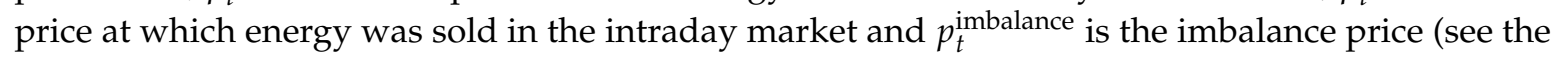
Notation list).

As an illustration, Figure 3 shows the monthly averaged day-ahead price and interquartile variability range, as well as the wind energy production at Parc de Bonneval and Parc de la Vènerie and the simulated daily income, computed with the $\mathrm{LR}_{S W}^{\mathrm{obs}}$ nowcasting model. Seasonal variability is clearly visible: the income is significantly higher in winter for the two farms due to higher production, and strong correlation between income and production. From the interquartile range, one can see that the distribution is not symmetric, especially in summer, when the third quartile is closer to the mean than the first quartile. Moreover, the seasonal pattern visible in the monthly average income is also reflected in the quartiles: for the two farms the interquartile range is smaller in summer than in winter. This can be explained by the lower variability of the production in summer than in winter. The variability of the day-ahead price which represents almost $90 \%$ of the total income is fairly similar in summer and in winter whereas the variability of energy production in winter is larger than in summer by about $50 \%$.

To sum up the workflow of the study, Figure 4 illustrates the methodology. It displays the forecasting aspects: how the different models are fitted and how they are used in an operational mode. It also displays the economic aspect: how we go from wind speed forecasting to income from production. The flowchart also exhibits the temporal aspect of the study linked to the three steps of the electricty market, as well as the different type of data that are used along the study workflow. 
(a) Day ahead price

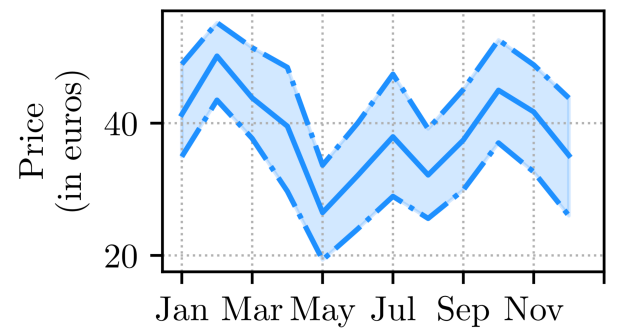

(b) Parc de Bonneval

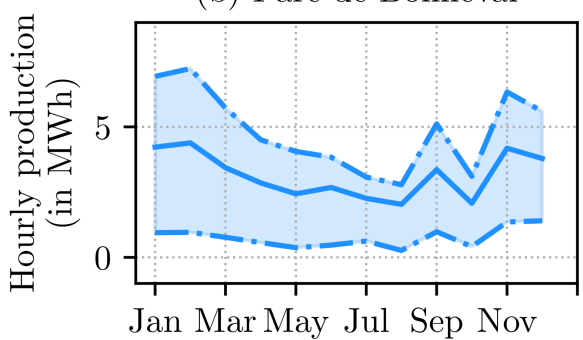

(d) Parc de Bonneval ( $\left.\mathrm{LR}_{\mathrm{SW}}^{\mathrm{obs}}\right)$

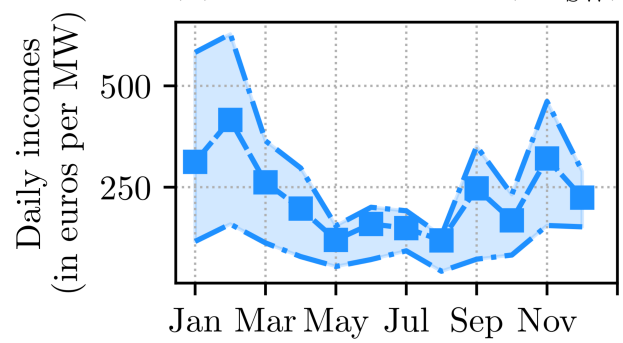

(c) Parc de la Vènerie

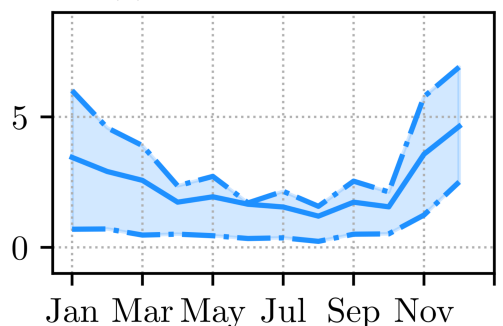

(e) Parc de la Vènerie $\left(\mathrm{LR}_{\mathrm{SW}}^{\mathrm{obs}}\right)$

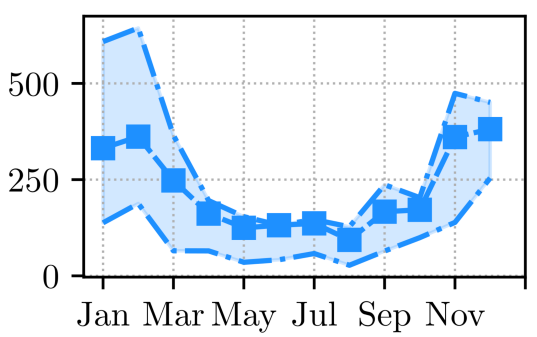

Figure 3. Panel (a): day-ahead price averaged over each month of the calendar year, together with the first and third quartiles for each month. Panels $(\mathbf{b}, \mathbf{c})$ : wind energy production at Parc de Bonneval and Parc de la Vènerie, averaged over each month with first and third quartiles for each month. Panels (d,e): simulated daily income, computed with the $\mathrm{LR}_{\mathrm{SW}}^{\mathrm{obs}}$ nowcasting model, averaged over each month, with quartiles for each month. Data and results are shown for the year 2015. 

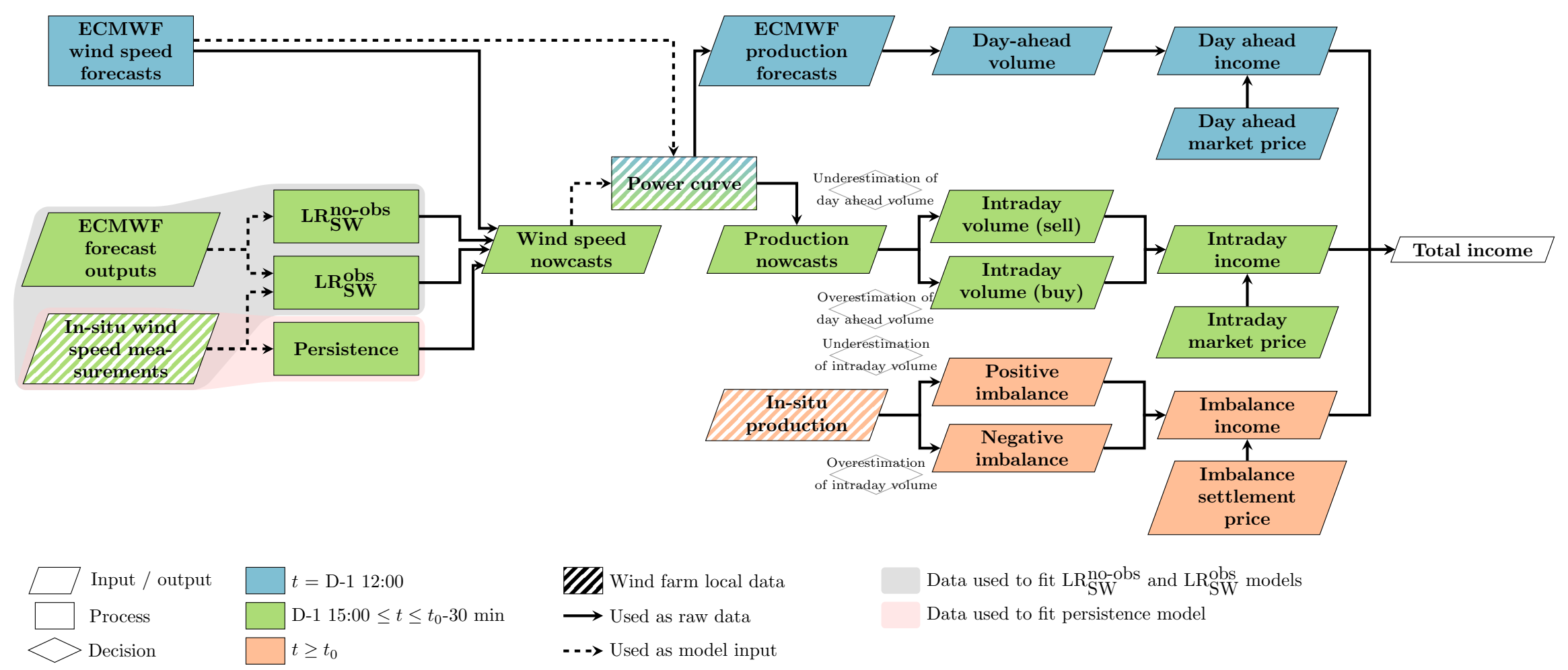

Wh Wind farm local data
$\longrightarrow$ Used as raw data
- - -> Used as model input

Figure 4. Workflow considered in this study. 


\section{Sources of Uncertainty in Wind Farm Income}

This study highlights two main sources of uncertainty in wind farm income. The first one is related to nowcasting errors. Nowcasting errors are expected to decrease when the delivery time comes closer. Figure 5 displays for the two wind farms the Normalized Root Mean Square Error (NRMSE) of the four available nowcasts from $\mathrm{LR}_{\mathrm{SW}}^{\mathrm{obs}}, \mathrm{LR}_{\mathrm{SW}}^{\text {no-obs }}$ and ECMWF models and from persistence. The NRMSE is defined as follows.

$$
\text { NRMSE }=\frac{\sqrt{\frac{1}{N} \sum_{i=1}^{N}\left(\hat{y}_{i}-y_{i}\right)^{2}}}{\tilde{Y}},
$$

where $\hat{y}_{i}$ is the $i$-th energy forecast and $y_{i}$ is the corresponding observation, $N$ refers to the number of forecasts used to compute the NRMSE, and $\tilde{Y}$ is the rated power (12 MW at Parc de Bonneval and 9.2 MW at Parc de la Vènerie).

As a reminder, $\mathrm{LR}_{\mathrm{SW}}^{\mathrm{obs}}$ is a linear regression with assimilation of observations and $\mathrm{LR}_{\mathrm{SW}}^{\mathrm{no}-\mathrm{obs}}$ is a linear regression without assimilation.
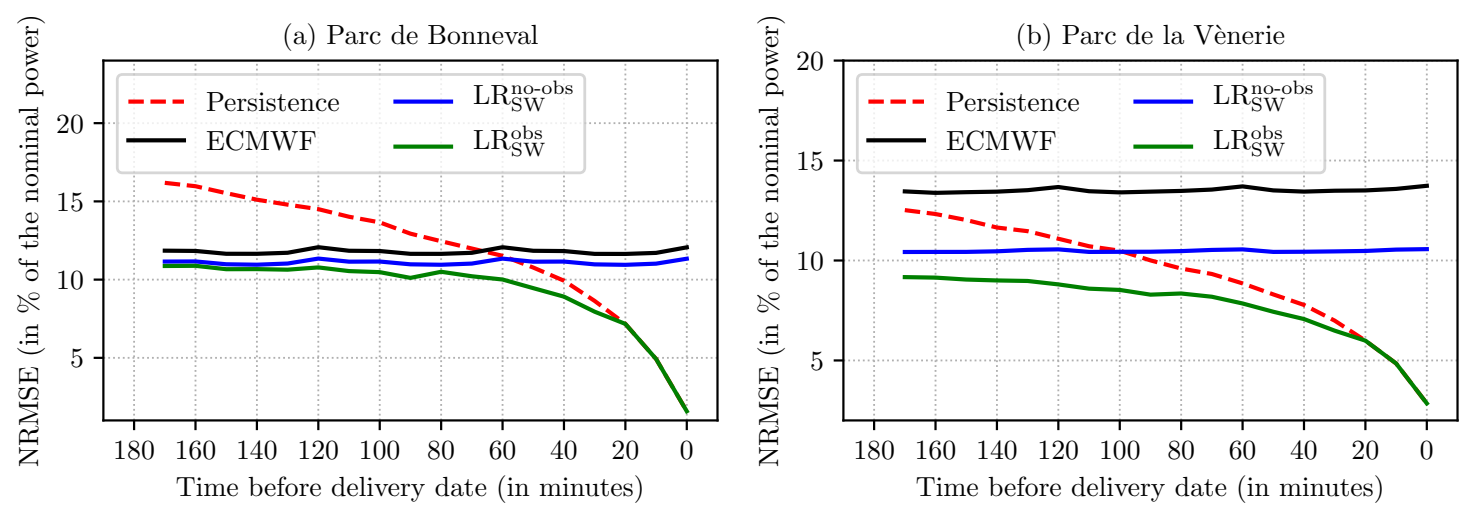

Figure 5. Forecasting errors for several forecast model as a function of lead time to delivery. Results for ECMWF, $\mathrm{LR}_{\mathrm{SW}}^{\mathrm{obs}}$ and $\mathrm{LR}_{\mathrm{SW}}^{\text {no-obs }}$ nowcasts as well as persistence are shown. The models are evaluated against persistence (red dashed line). Results for Parc de Bonneval (a) and for Parc de la Vènerie (b) are shown. The $x$-axis displays the time before the delivery date: $x=40$ means that the models are launched $40 \mathrm{~min}$ before the delivery date.

Figure 5 displays the NRMSE of the nowcasts as a function of lead time before the delivery date. For the two wind farms, the performance of ECMWF and LR $\mathrm{SW}_{\mathrm{SW}}^{\text {noobs }}$ do not depend on the time horizon. The NRMSE is around 11\% at Parc de Bonneval and between $11 \%$ and $14 \%$ at Parc de la Vènerie. When in situ measurements are added as explanatory variables in $\mathrm{LR}_{\mathrm{SW}}^{\mathrm{obs}}$, the error decreases as the forecast time horizon gets closer to the delivery time. The error from $\mathrm{LR}_{\mathrm{SW}}^{\mathrm{obs}}$ increases from $7.9 \%$ at Parc de Bonneval for 30 -min lead time, to $10.8 \%$ for $2 \mathrm{~h}$ lead time. For more details on the forecasting errors, interested readers are referred to [10].

Using $\mathrm{LR}_{\mathrm{SW}}^{\mathrm{obs}}$ nowcast, the optimal strategy should thus be to adjust the position in the intraday market as late as possible, i.e., $30 \mathrm{~min}$ before the delivery date. However, one needs to take into account the impact of price volatility which measures the risk associated with price fluctuations. If volatility is low, most of the time, an average price is obtained which means the associated risk is low. However, when the volatility is high it is whether possible to get a very good price (low purchase and high sale) or a very bad one (high purchase and low sale). As a result, transactions are much more risky. Intraday electricity market prices are non stationary. The number of transactions per unit time and the average price volatility strongly depend on the time remaining until delivery [14] and increase when the delivery time draws near.

Figure 6 displays the annual price variations on intraday in 2015 as a function of the balancing time all delivery date combined. The closer the delivery date, the larger the price variations. Moreover, 
the variations are larger for the buying price than for the selling price. It starts between $12.1 €$ and $12.3 € 3 \mathrm{~h}$ before the delivery date, up to between $13.4 €$ and $14.5 € 30 \mathrm{~min}$ before the delivery date. A larger variation means more risk for the producer. Consequently, from Figure 6, the optimal scenario seems to be a balancing time as early as possible.

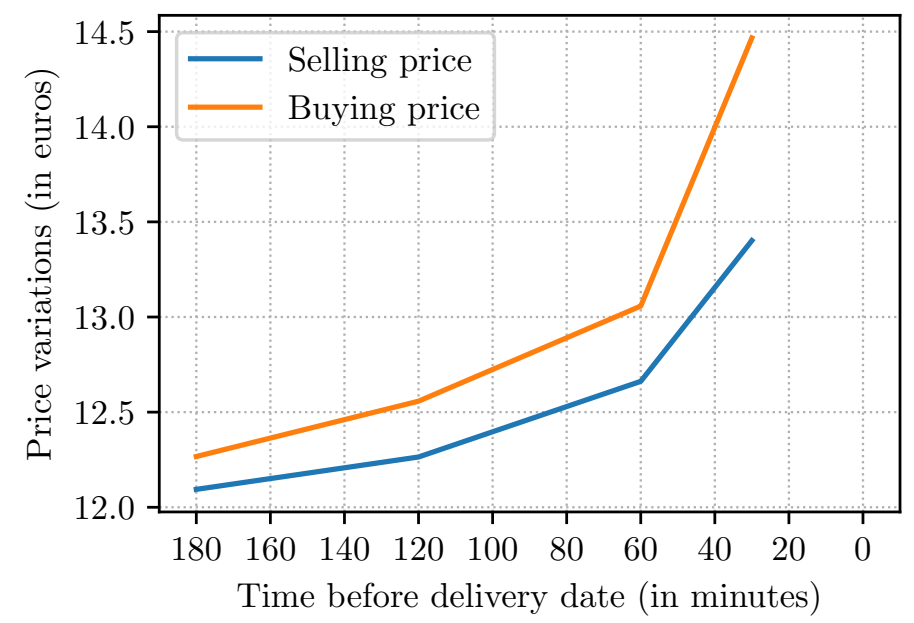

Figure 6. Price variations in euros as a function of time before delivery date. Blue line in for the selling price on intraday and orange line is for the buying price.

Since the forecasting model is expected to be the most accurate close to the delivery date, while larger price variations introduce additional uncertainty at this time, one can assume the existence of an optimal time to balance in the intraday market. As expected from Figure 5, the optimal time should depend on the nowcast model. In the following, the results are analyzed using $\mathrm{LR}_{\mathrm{SW}}^{\mathrm{obs}}$ model which displays the best performance.

\section{Results}

To determine the optimal balancing time in the intraday market, we introduce three case studies:

1. The case without nowcast available. In this case, the difference between the production sold in the day-ahead market and the real production is compensated via imbalance settlement price.

2. The case with a perfect nowcast available. There is no imbalance penalty.

3. The case with a realistic nowcast available. The quantities sold in the intraday and day-ahead markets differ from the real production, so the producer may have to pay an imbalance penalty.

To evaluate the impact of the four available nowcasts ( $\mathrm{LR}_{\mathrm{SW}}^{\mathrm{obs}}, \mathrm{LR} \mathrm{SW}_{\mathrm{SW}}^{\text {no-obs }}, \mathrm{ECMWF}$ or persistence), we define a score that represents the difference in income between the case where a realistic nowcast is used and the case without nowcast available:

$$
\Delta I=I_{\mathrm{tot}}^{\text {Forecast }}-I_{\mathrm{tot}}^{\text {No forecast }}
$$

The score is computed weekly and is expressed in euros per MW of installed capacity. It is positive (resp. negative) for income gain (resp. loss) consequent to the use of nowcast information.

Figure 7 displays $\Delta I$ at Parc de Bonneval and Parc de la Vènerie, for the four nowcasts. At Parc de Bonneval, except for a strong peak from persistence in March, $\mathrm{LR}_{\mathrm{SW}}^{\mathrm{obs}}$ nowcasts outperform the others. The quantity $\Delta I$ is on average positive showing the added-value of the use of nowcast information. The annual averaged values are 58.0 €/MW for $\mathrm{LR}_{\mathrm{SW}}^{\mathrm{obs}}, 17.3 € / \mathrm{MW}$ for $\mathrm{LR}_{\mathrm{SW}}^{\text {no-obs }}, 15.2 € / \mathrm{MW}$ for ECMWF and $35.1 € / \mathrm{MW}$ for persistence. However, the variation range of $\Delta I$ can reach $100 \%$ at times. At Parc de la Vènerie, such as at Parc de Bonneval, the use of a nowcasts increases the income. This income increase is larger than at Parc de Bonneval, except for ECMWF. The annual averaged values 
are 84.1 $€ / \mathrm{MW}$ for $\mathrm{LR}_{\mathrm{SW}}^{\mathrm{obs}}, 24.5 € / \mathrm{MW}$ for $\mathrm{LR}_{\mathrm{SW}}^{\text {no-obs }}, 2.8 € / \mathrm{MW}$ for ECMWF and $67.0 € / \mathrm{MW}$ for persistence. For the two wind farms, $\mathrm{LR}_{\mathrm{SW}}^{\mathrm{obs}}$ model shows the best performance.

(a) Parc de Bonneval (ICAP=12 MW)

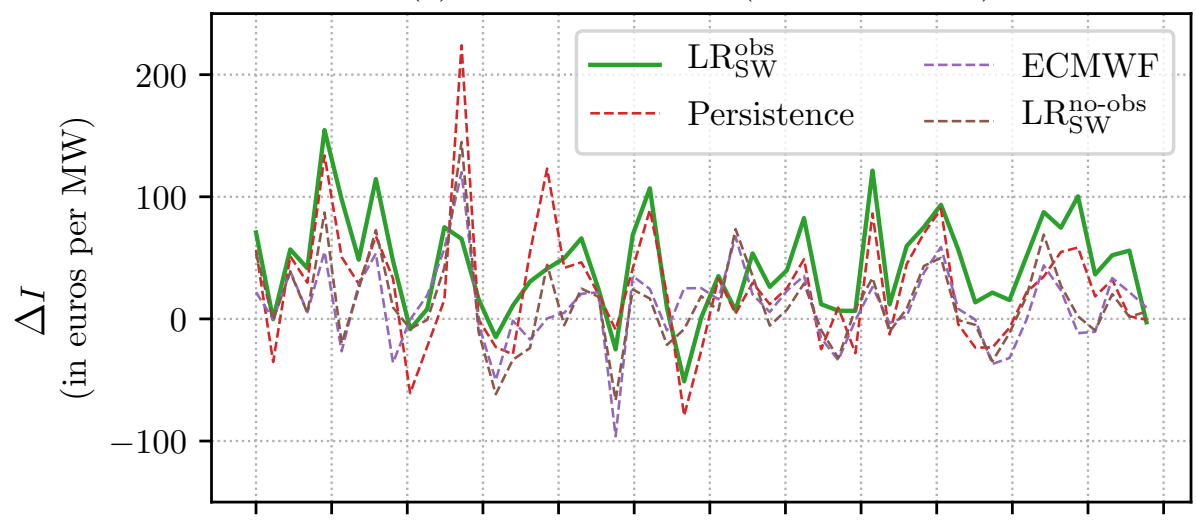

(b) Parc de la Vènerie (ICAP=9.2 MW)

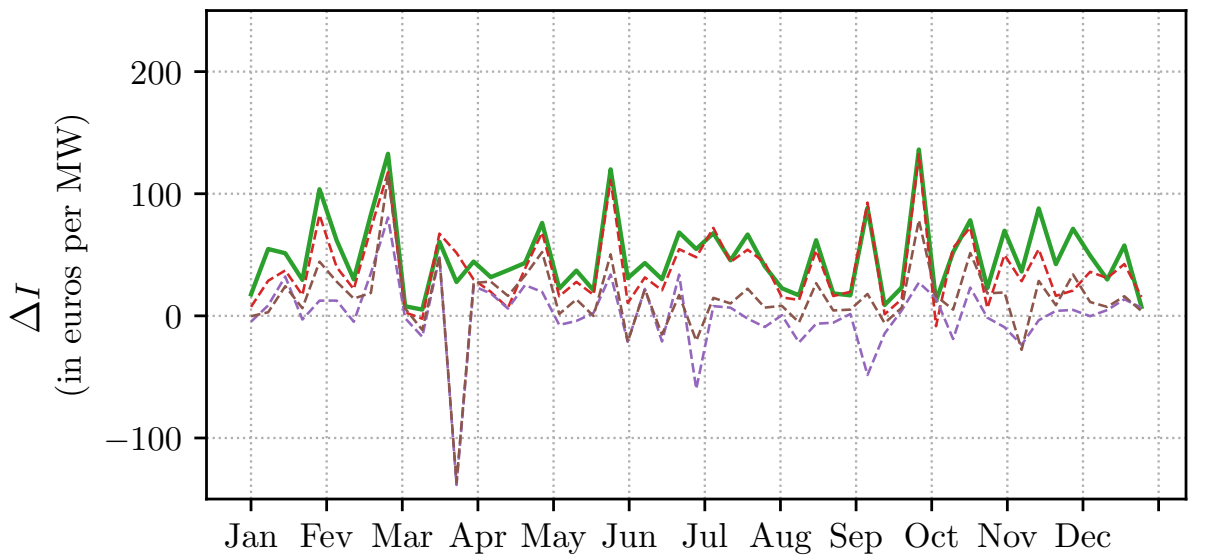

Figure 7. $\Delta I$ (Equation (7)) normalized by the installed capacity at Parc de Bonneval (a) and Parc de la Vènerie (b). It is expressed in euros per MW and it is computed weekly.

To determine more precisely the added value of nowcast information, we separate the total income into three sources: income from day-ahead market, income from intraday market and income from imbalance settlement. Particular attention is given to $I_{\text {intraday }}$ and $I_{\text {imbalance }}$ as they have a stronger dependence on the nowcast. We consider four balancing times: $30 \mathrm{~min}, 1 \mathrm{~h}, 2 \mathrm{~h}$ and $3 \mathrm{~h}$ before the delivery time. The quantity $I_{\text {day-ahead }}$ is the same for all four scenarios, since it does not depend on the balancing time. For each balancing time, we compare two cases: the case with perfect nowcasts and the case with $\mathrm{LR}_{\mathrm{SW}}^{\mathrm{obs}}$ nowcast. In each case, the quantity sold in the day-ahead market is based on the ECMWF forecasts (see Section 2.2).

Figure 8 displays the daily income in euros per MW from the intraday market, averaged over each month, at Parc de Bonneval (Figure 8a,b) and at Parc de la Vènerie (Figure 8c,d). The two farms exhibit similar behavior whatever the forecast (realistic or perfect), with higher revenues during spring and summer (with an exception in May), than during fall and winter. The income from the intraday market is negative in winter and positive in summer. This means that in winter, $F_{t}^{\mathrm{LR}}<F_{t}^{\mathrm{Ob} S \mathrm{EWF}}$, and the balancing consists of buying energy in the intraday market, while in summer $F_{t}^{\mathrm{LR}} \mathrm{SW}_{t}^{\mathrm{obs}}>F_{t}^{\mathrm{ECMWF}}$, and the balancing consists of selling a surplus of energy in the intraday market. The difference between the four balancing strategies is more pronounced in the case of realistic forecast, as for perfect foreast, the difference is only due to the difference in market prices. 


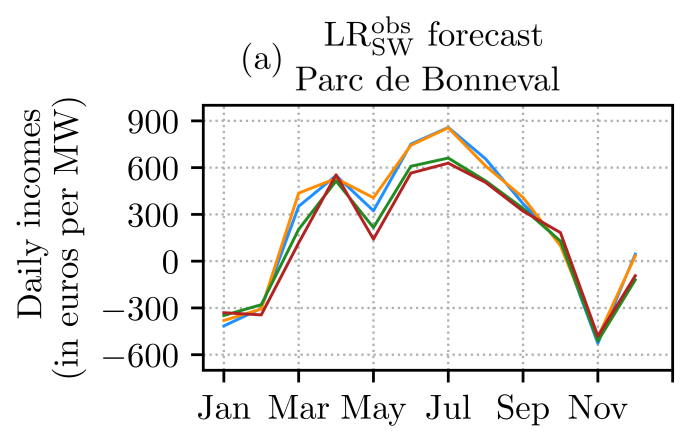

(c) LR $\mathrm{LW}_{\mathrm{SW}}^{\mathrm{bs}}$ forecast

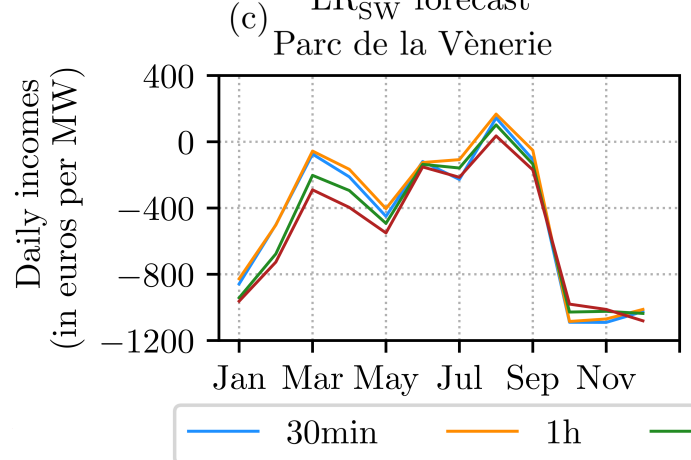

(b) Perfect forecast Parc de Bonneval

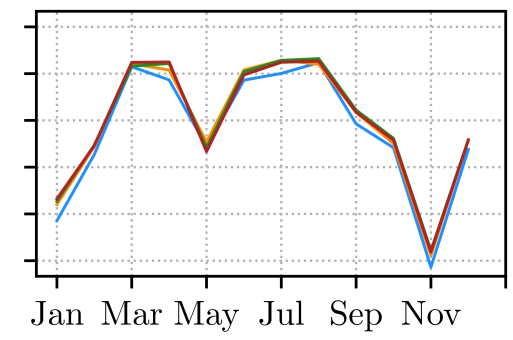

(d) Perfect forecast

(d) Parc de la Vènerie

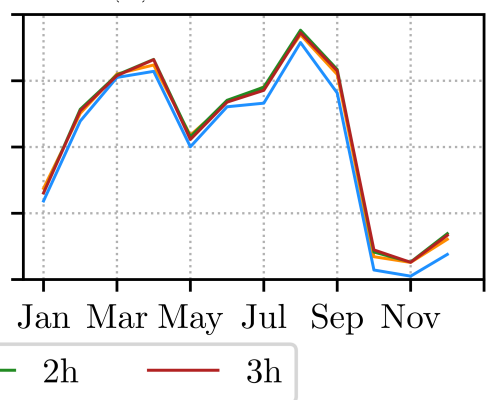

Figure 8. Daily income from intraday market averaged over months at Parc de Bonneval ((a) and (b)) and at Parc de la Vènerie ((c) and (d)) in 2015. For both farms, four different balancing times (30 min, $1 \mathrm{~h}, 2 \mathrm{~h}$, and $3 \mathrm{~h}$ before the delivery date) are shown. Panel (a) (resp. (c)) displays the results when the nowcast is provided by LR $\mathrm{SW}_{\mathrm{SW}}^{\mathrm{ob}}$ at Parc de Bonneval (resp. Parc de la Vènerie), and panel (b) (resp. (d)) assumes perfect knowledge of the realized production at Parc de Bonneval (resp. Parc de la Vènerie).

More quantitatively, Table 3 shows how frequently the energy balanced in the intraday market $P_{\text {intraday }}$ exceeds different thresholds. Four thresholds are considered: $P_{\text {intraday }}<-20 \%$ of the installed capacity (ICAP) (large negative forecast errors), $P_{\text {intraday }}<0 \mathrm{MWh}$ (moderately negative forecast errors), $P_{\text {intraday }}>0 \mathrm{MWh}$ (moderately positive forecast errors) and $P_{\text {intraday }}>20 \%$ ICAP (large positive forecast errors). The first four rows display the results for the four balancing strategies for $\mathrm{LR}_{\mathrm{SW}}^{\mathrm{obs}}$ nowcast, while the last row displays the results for perfect nowcast. At Parc de Bonneval, the occurrence of positive errors (around 53\%) is larger than that of negative errors (around 41\%) for both $\mathrm{LR}_{\mathrm{SW}}^{\mathrm{obs}}$ and perfect nowcasts. Therefore, in most cases, the balancing is done by selling excess energy in the intraday market. At Parc de la Vènerie, the occurrences of negative and positive errors are similar. However, the occurrence of large negative errors is significantly higher than the occurrence of large positive errors. Therefore, in most cases, the balancing consists of buying a lack of energy on intraday. This explains the results of Figure 8. As the balancing at Parc de Bonneval consists mainly in selling an energy surplus, the income is therefore positive (Figure 8a,b). However, as the balancing at Parc de la Vènerie consists mainly in buying an energy deficit, the income from this balancing tends to be negative (Figure $8 \mathrm{c}, \mathrm{d}$ ).

The last source of income that depends on nowcasting and on balancing strategy is the imbalance settlement. Figure 9 shows the monthly averages of the daily income from imbalance settlement $P_{t}^{\text {imbalance }}$ for Parc de Bonneval for 2015. The income is mostly negative at Parc de Bonneval, except in February. At Parc de la Vènerie, a similar curve is found but shifted to more positive values. 
Table 3. Occurrence of $P_{\text {intraday }}$ above or below various thresholds, where $P_{\text {intraday }}$ is defined as the difference between the production nowcast and the production sold in the day-ahead market. Occurrences of large negative errors $\left(P_{\text {intraday }}<-20 \%\right.$ ICAP), moderate negative errors $\left(P_{\text {intraday }}<0 \mathrm{MWh}\right)$, moderate positive errors $\left(P_{\text {intraday }}>0 \mathrm{MWh}\right)$ and large positive errors ( $P_{\text {intraday }}>20 \%$ ICAP) are indicated for Parc de Bonneval and Parc de la Vènerie and four balancing times ( $30 \mathrm{~min}, 1 \mathrm{~h}, 2 \mathrm{~h}$ and $3 \mathrm{~h}$ before the delivery date) using the $\mathrm{LR}_{\mathrm{SW}}^{\mathrm{obs}}$ (first four rows) and perfect (last row) nowcasts.

(a) Parc de Bonneval

\begin{tabular}{ccccc}
\hline & $\begin{array}{c}P_{\text {intraday }}<-20 \% \text { ICAP } \\
\text { Occurrence (\%) }\end{array}$ & $\begin{array}{c}P_{\text {intraday }}<\mathbf{0 ~ M W h} \\
\text { Occurrence (\%) }\end{array}$ & $\begin{array}{c}P_{\text {intraday }}>\mathbf{0 ~ M W h} \\
\text { Occurrence (\%) }\end{array}$ & $\begin{array}{c}P_{\text {intraday }}>\mathbf{2 0 \%} \text { ICAP } \\
\text { Occurrence (\%) }\end{array}$ \\
\hline $30 \mathrm{~min}$ & 3.6 & 41.0 & 52.9 & 4.7 \\
$1 \mathrm{~h}$ & 3.8 & 40.8 & 53.3 & 4.9 \\
$2 \mathrm{~h}$ & 3.0 & 41.0 & 53.3 & 2.6 \\
$3 \mathrm{~h}$ & 2.8 & 40.9 & 53.5 & 2.3 \\
Perfect forecast & 7.0 & 41.9 & 52.3 & 10.0 \\
\hline
\end{tabular}

(b) Parc de la Vènerie

\begin{tabular}{ccccc}
\hline & $\begin{array}{c}P_{\text {intraday }}<-20 \% \text { ICAP } \\
\text { Occurrence (\%) }\end{array}$ & $\begin{array}{c}P_{\text {intraday }}<\mathbf{0 ~ M W h} \\
\text { Occurrence (\%) }\end{array}$ & $\begin{array}{c}P_{\text {intraday }}>\mathbf{0 ~ M W h} \\
\text { Occurrence (\%) }\end{array}$ & $\begin{array}{c}P_{\text {intraday }}>\mathbf{2 0 \%} \text { ICAP } \\
\text { Occurrence (\%) }\end{array}$ \\
\hline $30 \mathrm{~min}$ & 6.1 & 50.1 & 49.9 & 2.7 \\
$1 \mathrm{~h}$ & 6.5 & 50.3 & 49.6 & 3.0 \\
$2 \mathrm{~h}$ & 6.5 & 51.6 & 48.3 & 2.1 \\
$3 \mathrm{~h}$ & 6.3 & 52.2 & 47.8 & 1.7 \\
Perfect forecast & 6.4 & 48.1 & 51.7 & 3.6 \\
\hline
\end{tabular}

(a) Parc de Bonneval

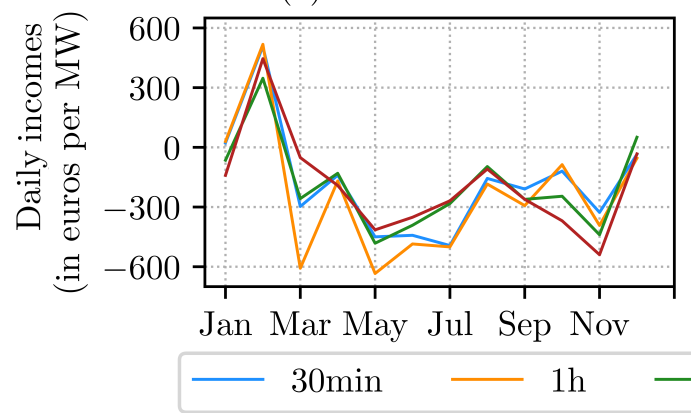

(b) Parc de la Vènerie

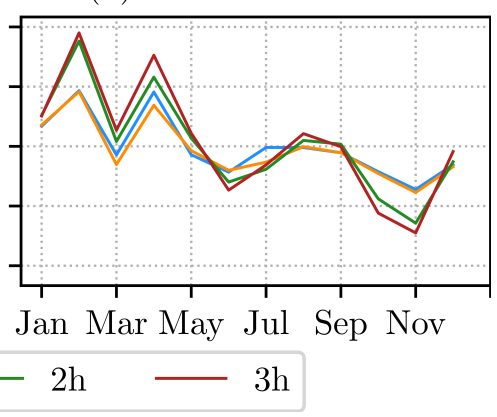

Figure 9. Daily income from imbalance averaged over months at Parc de Bonneval in 2015 (a) and at Parc de la Vènerie (b) in 2015 for four different balancing strategies (30 $\mathrm{min}, 1 \mathrm{~h}, 2 \mathrm{~h}$ and $3 \mathrm{~h}$ before the delivery date).

The income from imbalance is the difference between the real production and the production nowcast, multiplied by the imbalance settlement price. Table 4 shows the same information as Table 3

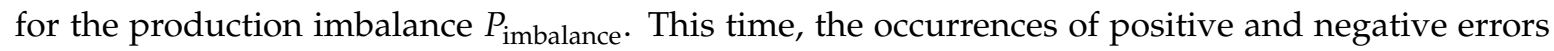
are very similar for all balancing times. In these conditions, the positive errors cannot compensate for the large difference between settlement prices for positive and negative imbalance. Indeed, the average settlement price for positive imbalances in 2015 is $32 €$ while the average penalty for negative imbalances in 2015 is $45 €$, explaing the negative income. Also, the occurrence of large errors increases with increasing lead time. When the nowcast is provided $30 \mathrm{~min}$ before the delivery date, the occurrenvce of large negative errors exceeds that of large positive errors, but the occurrence remains low $(<1 \%)$. When balancing is done $1 \mathrm{~h}$ before the delivery date, the occurrences of large negative and positive errors are very similar. Combined with the large difference between penalties for positive and negative imbalance, this suggests that such situations should lead to the lowest income from imbalance settlement. Finally, when balancing is done $2 \mathrm{~h}$ or $3 \mathrm{~h}$ before the delivery date, the occurrence of large positive errors iexceeds that of large negative errors suggesting a positive income from imbalance. 
At Parc de la Vènerie, the occurrence of positive errors is significantly larger than that of negative errors, compensating the difference in penalty rates. It therefore leads to a positive income from imbalance settlement. The different result for the two farms is linked to the nowcast error which put in evidence the impact of nowcast performance assessment. It also shows that for other farms, an a priori study of the nowcast bias is key information on the wind farm income.

Table 4. Frequency at which $P_{\text {imbalance }}$ exceeds different thresholds. Percentages for the large negative errors ( $P_{\text {imbalance }}<-20 \%$ ICAP), the moderately negative errors ( $P_{\text {imbalance }}<0 \mathrm{MWh}$ ), the moderately positive errors ( $P_{\text {imbalance }}>0 \mathrm{MWh}$ ) and the large positive errors $\left(P_{\text {imbalance }}>20 \%\right.$ ICAP) are shown. Table $4 \mathrm{a}$ shows the results for Parc de Bonneval while Table $4 \mathrm{~b}$ shows the results for Parc de la Vènerie. In both cases the results are shown for four balancing times $(30 \mathrm{~min}, 1 \mathrm{~h}, 2 \mathrm{~h}$ and $3 \mathrm{~h}$ before the delivery date). The last row correspond to the case where no nowcast is available.

(a) Imbalance when using LR $\mathrm{SW}_{\mathrm{SW}}^{\mathrm{obs}}$ nowcasting model for Parc de Bonneval

\begin{tabular}{ccccc}
\hline & $\begin{array}{c}P_{\text {imbalance }}<-\mathbf{2 0} \% \text { ICAP } \\
\text { Occurrence (\%) }\end{array}$ & $\begin{array}{c}P_{\text {imbalance }}<\mathbf{0} \\
\text { Occurrence (\%) }\end{array}$ & $\begin{array}{c}P_{\text {imbalance }}>\mathbf{0} \\
\text { Occurrence (\%) }\end{array}$ & $\begin{array}{c}P_{\text {imbalance }}>\mathbf{2 0 \%} \text { ICAP } \\
\text { Occurrence (\%) }\end{array}$ \\
\hline $30 \mathrm{~min}$ & 0.5 & 46.3 & 46.2 & 0.2 \\
$1 \mathrm{~h}$ & 1.3 & 46.8 & 46.1 & 1.1 \\
$2 \mathrm{~h}$ & 2.4 & 47.6 & 47.0 & 3.4 \\
$3 \mathrm{~h}$ & 2.7 & 47.4 & 47.5 & 4.2 \\
No nowcast & 7.0 & 41.9 & 52.3 & 10.0 \\
\hline
\end{tabular}

(b) Imbalance when using $\mathrm{LR}_{\mathrm{SW}}^{\mathrm{obs}}$ nowcasting model for Parc de la Vènerie

\begin{tabular}{ccccc}
\hline & $\begin{array}{c}P_{\text {imbalance }}<-\mathbf{2 0} \% \text { ICAP } \\
\text { Occurrence (\%) }\end{array}$ & $\begin{array}{c}P_{\text {imbalance }}<\mathbf{0} \\
\text { Occurrence (\%) }\end{array}$ & $\begin{array}{c}P_{\text {imbalance }}>\mathbf{0} \\
\text { Occurrence (\%) }\end{array}$ & $\begin{array}{c}P_{\text {imbalance }}>\mathbf{2 0 \%} \text { ICAP } \\
\text { Occurrence (\%) }\end{array}$ \\
\hline $30 \mathrm{~min}$ & 0.4 & 43.3 & 56.5 & 0.0 \\
$1 \mathrm{~h}$ & 0.5 & 45.5 & 54.3 & 0.4 \\
$2 \mathrm{~h}$ & 1.1 & 45.7 & 54.2 & 2.0 \\
$3 \mathrm{~h}$ & 1.5 & 45.7 & 54.3 & 2.8 \\
No nowcast & 6.4 & 48.1 & 51.7 & 3.6 \\
\hline
\end{tabular}

To understand the combined effect of the three sources of income, we compare in Figure 10 the total annual income for 2015 for the three case studies and for the four available nowcasts. For the two farms, and without surprise, the largest income is obtained when perfect forecast is available (which is never the case). The lowest income is found when no nowcast is used. At Parc de la Vènerie, this lowest income is also reached when using ECMWF forecast as a nowcasting tool as ECMWF forecast of wind energy production performs poorly at this location. Indeed, the forecasts are provided at $100 \mathrm{~m}$, and despite height correction, there is still a chance of overestimating the production. Such a bias would produce negative imbalance, resulting in a loss of income. Without surprise, the $\mathrm{LR}_{\mathrm{SW}}^{\mathrm{obs}}$ model, assimilating wind farm data and calibrated specifically on each wind farm outperforms the other models.

However, at Parc de Bonneval (resp. Parc de la Vènerie), the additional income of $L R_{S W}^{\text {obs }}$ nowcast with respect to the absence of nowcast information is larger than $20 \mathrm{k} €$ (resp. $30 \mathrm{k} €$ ). The income loss of $\mathrm{LR}_{\mathrm{SW}}^{\mathrm{obs}}$ nowcast with respect to a perfect nowcast is around $30 \mathrm{k} €$ (resp. $13 \mathrm{k} €$ ). The difference between the balancing strategies is even much lower, with additional gain of the order of 1 to $2 \mathrm{k} €$. Given these numbers, it is clear that the balancing strategy is less important than having access to an accurate nowcast. 

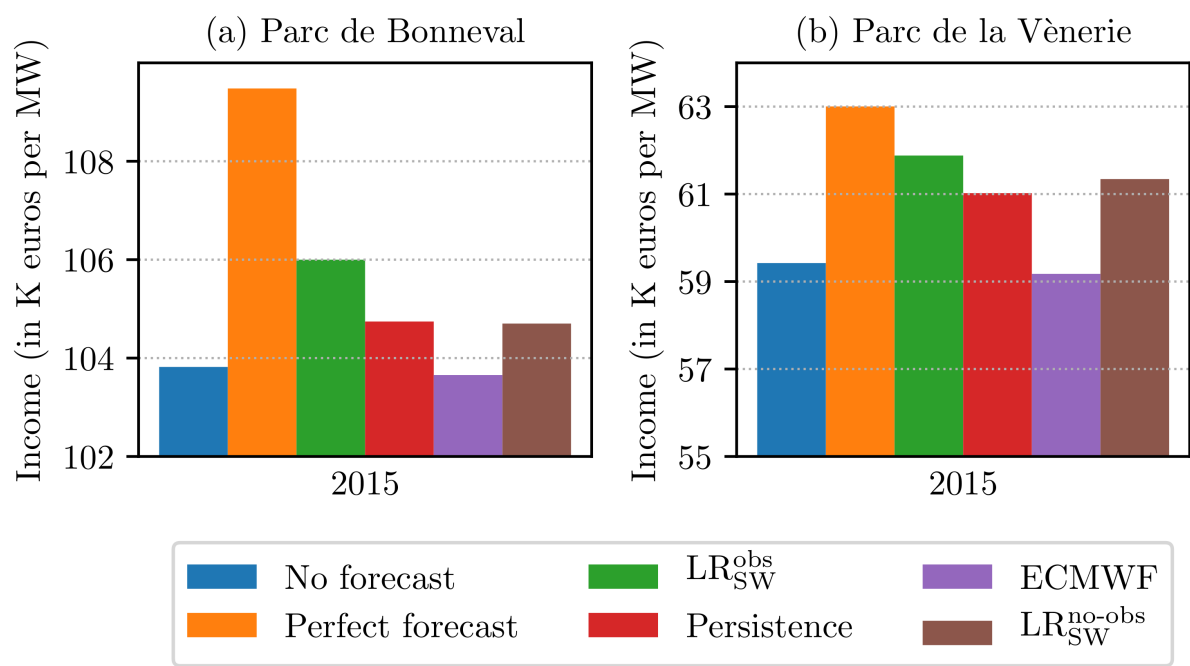

Figure 10. Aggregate income for 2015 for Parc de Bonneval (a) and Parc de la Vènerie (b). For both panels, we present the results for the case where no nowcast is available (blue bar), the case where the nowcast is perfect (orange bar), $\mathrm{LR}_{\mathrm{SW}}^{\mathrm{obs}}$ nowcasting model (dowscaling model with assimilation, green bar), persistence (red bar), ECMWF (violet bar), and $\mathrm{LR}_{\mathrm{SW}}^{\text {no-obs }}$ model (downscaling model without assimilation, brown bar). The scale is different from one Figure to another.

To extend the scope of this study, we apply the methodology to the six wind farms shown in Figure 1. Results are shown in Figure 11. As the data from wind farms are not available for the same year and for the sake of consistency, we make the following adjustments to the methodology:

1. for the three considered years, only $24 \mathrm{~h}$ lead time forecasts were available from ECMWF. To determine the day-ahead bids, we therefore use the forecasts starting at 1200 UTC on the day before delivery, with horizon at 12:00 on the delivery day. For the last twelve hours of the delivery day, we use the last available lead time from ECMWF.

2. we only have access to the intraday order book for 2015. For more consistency, we therefore use the intraday price data available on the EpexSPOT website for the 6 wind farms. The website provides the last intraday price, without distinction between purchase price and selling price. Then, to make the simulations more realistic, we add a spread to this price. As mention above, the average intraday selling price in 2015 is around $31 €$ while the average intraday buying price for the year 2015 is around $33 €$, so the average spread in the intraday market is $2 €$. Then, we add $1 €$ to the EPEX price to obtain the buying price and subtract $1 €$ to obtain the selling price.

Despite those simplifications, the conclusions are the same as those inferred from Figure 10. 

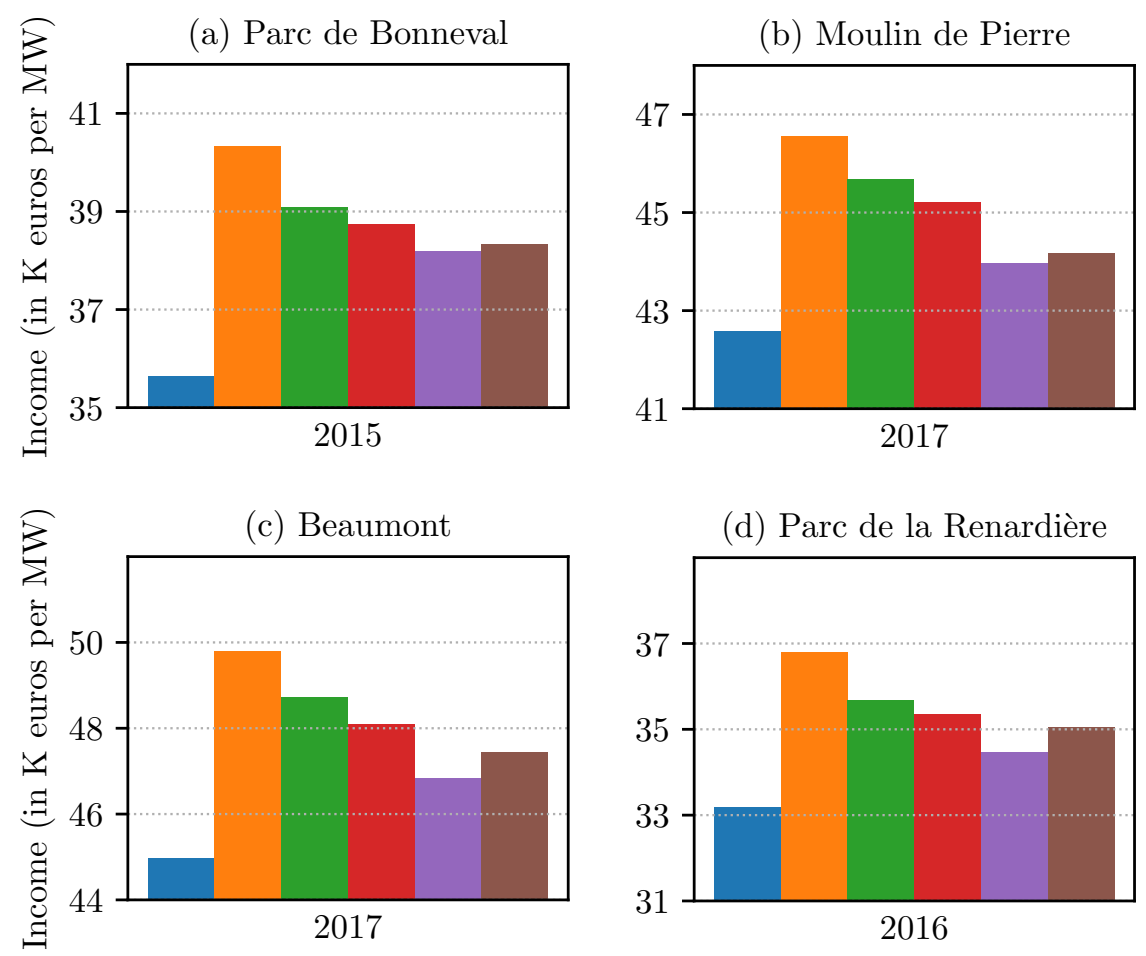

(d) Parc de la Renardière
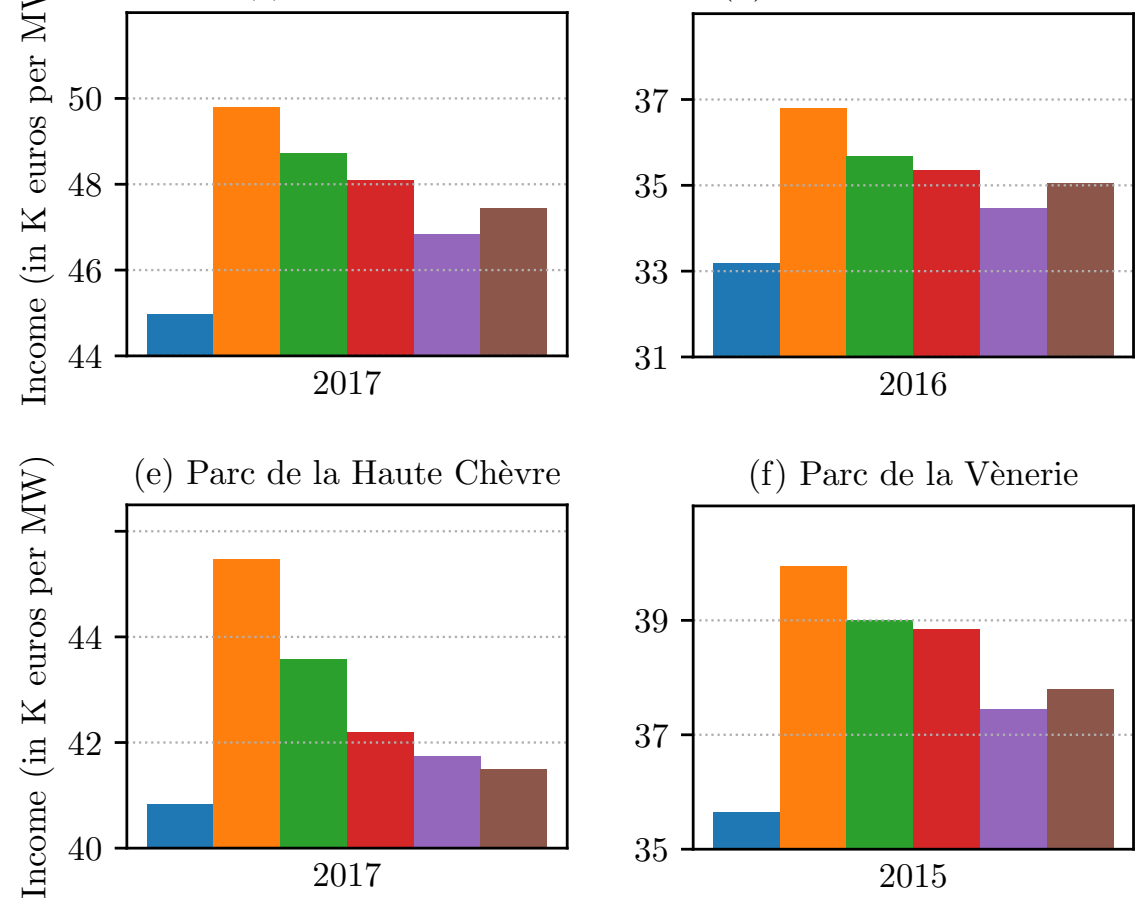

(f) Parc de la Vènerie
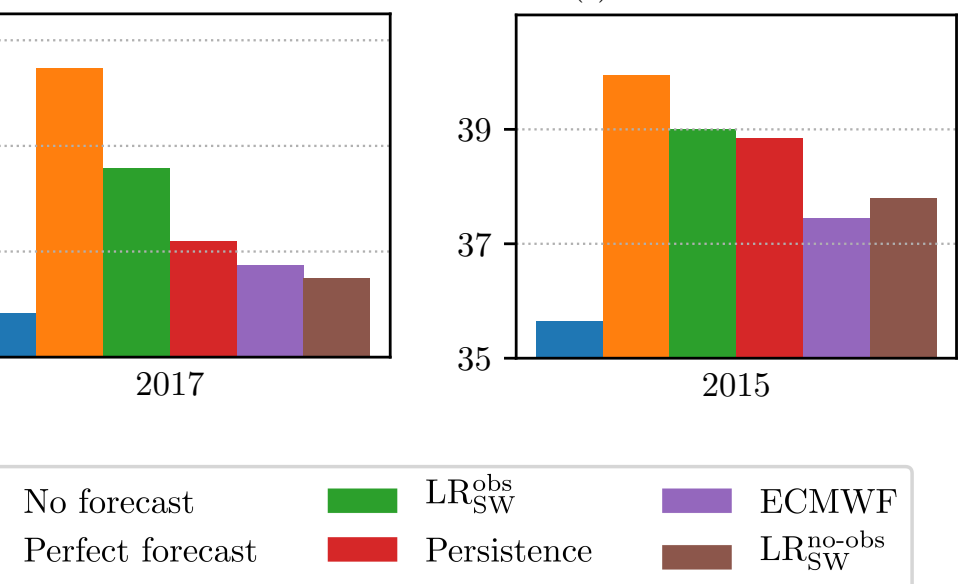

Figure 11. Same as Figure 10 for the six wind farms. Subfigure (a) shows the results for Parc de Bonneval, (b) for Moulin de Pierre, (c) for Beaumont, (d) for Parc de la Renardière, (e) for Parc de la Haute Chèvre and subfigure (f) shows the results for Parc de la Vènerie. A few changes in the methodology must be noted. (1) for day-ahead bids we use the ECMWF forecasts from $12 \mathrm{~h}$ ahead to $24 \mathrm{~h}$ ahead and for the last twelve hours, we use the last available lead time from ECMWF. (2) for intraday bids, we use the last price, available on EpexSPOT website, without distinction between purchase price and selling price.

\section{Conclusions}

This paper aims at quantifying the economic value for a wind energy producer of nowcast from $30 \mathrm{~min}$ to $3 \mathrm{~h}$ lead time to bid on the intraday market, by using wind speed and energy production data of six wind farms as well as electricity prices. Based on these data, several key messages can be inferred. The optimal balancing time on the intraday market results from a trade-off between the degradation of the nowcast performance with increasing lead-time to delivery, and the increasing price volatility when approaching the delivery time. However, balancing at the optimal moment only brings 
an additional income of less than $1 \%$ of the annual income for the wind farms considered in the study, whereas the use of an accurate nowcast can bring an additional gain of about $3-4 \%$.

A second key message is that the combination of wind energy nowcast errors and price volatility is non trivial as not only the distribution of the wind energy nowcast errors strongly impacts the income (symmetrical or asymmetrical error distribution) but also the difference of selling and buying price which can differ significantly on the imbalance market. Therefore, even a non-biased symmetrical nowcast error distribution can induce an income loss as the sold energy surplus cannot compensate financially the bought energy deficit. An asymmetrical nowcast error distribution can mitigate or amplify the price effect. Therefore an accurate assessment of the nowcast error distribution is key to anticipate the risk the wind energy producer takes when bidding on the intraday market, or worse the penalties on the imbalance market.

This study presents a scenario where the wind energy producers have access to the electricity market. However in practice this access is restricted to so-called aggregators. They link the electricity producers and the electricity market. After buying the production of partners, they sell it, either to customers or on the market. In this study, the production of each farm is individually sold on the market. The methodology is valid; however, the numbers mentioned are not realistic since they must be transposed to the aggregator level.

A second source of uncertainty, which is not addressed in this study, is related to the ECMWF forecasts $48 \mathrm{~h}$ ahead. These forecasts are used to sell the production on the day-ahead market. They are computed over a grid of $0.125^{\circ}$ in latitude and longitude and a linear interpolation is performed in order to retrieve the forecast at the wind farm location. Such resolution is too coarse to account for local terrain inhomogeneities. Therefore, forecasts on such time and spatial resolution are often biased, as is shown in this study, with a significant impact on the income assessment. A statistical bias correction should be applied to reduce uncertainty and remove the bias. This could modify the quantity that needs to be balanced on intraday, and change the impact of the nowcasting models.

Another potential source of uncertainty affecting the results of our study is related to the use of market prices of electricity. Our study used mostly data from 2015 with some examples based on 2016 and 2017. However, the electricity markets are non stationary and the prices may fluctuate year to year due to external factors, such as the growing penetration of renewables, variations in fuel prices, changes in market structure, etc. Thus, specific income values given in our paper for specific wind farms may not be representative of the general situation. However, the relative performance of different forecasting methods is stable over different wind farms and different years.

Author Contributions: A.D., P.D., J.B. and P.T. developed and validated the methodology. A.D. wrote the original draft preparation with support from P.D., J.B. and P.T. C.B. collected and prepared the data. All authors have read and agreed to the published version of the manuscript.

Funding: This research was supported by 3rd Programme d'Investissements d'Avenir [ANR-18-EUR-0006-02] and by the Foundation of Ecole polytechnique (Chaire "Défis Technologiques pour une Énergie Responsable"). It was also supported by the Zephyr ENR research contract X/2016COLLR0242-CNRS/148264. Peter Tankov gratefully acknowledges financial support from the ANR (project EcoREES ANR-19-CE05-0042) and from the FIME Research Initiative.

Acknowledgments: This research was produced within the framework of Energy4Climate Interdisciplinary Center (E4C) of IP Paris and Ecole des Ponts ParisTech. We thank Zephyr ENR for providing the data.

Conflicts of Interest: The authors declare no conflict of interest.

\section{Acronym}

ICAP Installed capacity 


\section{Notations}

\begin{tabular}{|c|c|}
\hline $\mathrm{LR}_{\mathrm{SW}}^{\text {no-obs }}$ & $\begin{array}{l}\text { Downscaling model for wind energy nowcasting. Linear regression using as explanatory } \\
\text { variables the output from ECMWF model }\end{array}$ \\
\hline LR $\mathrm{SW}$ & $\begin{array}{l}\text { Downscaling model for wind energy nowcasting. Linear regression using as explanatory } \\
\text { variables the output from ECMWF model and the in-situ measurements }\end{array}$ \\
\hline$I_{t}^{\text {tot }}$ & Total income (from day ahead, intraday and imbalance markets) at time $t$ \\
\hline$I_{t}^{\text {day-ahead }}$ & Income from day ahead at time $t$ \\
\hline$I_{t}^{\text {intraday }}$ & Income from intraday at time $t$ \\
\hline$I_{t}^{\text {imbalance }}$ & Income from imbalance at time $t$ \\
\hline$F_{t}^{\mathrm{ECMWF}}$ & $\begin{array}{l}\text { Wind energy forecast (in MWh) from ECMWF model at time } t \text { (wind speed forecast } \\
\text { converted using the power curve) }\end{array}$ \\
\hline$F_{t}^{\mathrm{LR}}$ & Wind energy forecast (in $\mathrm{MWh}$ ) from $\mathrm{LR}_{\mathrm{SW}}^{\mathrm{obs}}$ model at time $t$ \\
\hline$F_{t}^{\text {real }}$ & Real production (in MWh) measured at time $t$ \\
\hline$p_{t}^{\text {day-ahead }}$ & Electricity price at time $t$ from day ahead market \\
\hline$p_{t}^{\text {intraday }}$ & Electricity price at time $t$ from intraday \\
\hline$p_{t}^{\text {imbalance }}$ & Electricity price at time $t$ from imbalance settlement \\
\hline$P_{\text {intraday }}$ & Energy quantity (in MWh) that is balanced (buy or sold) via intraday \\
\hline$P_{\text {imbalance }}$ & Energy quantity (in MWh) that is balanced via the imbalance settlements \\
\hline
\end{tabular}

\section{References}

1. Nielsen, L.H.; Morthorst, P.E.; Skytte, K. Wind power and a liberalised north european electricity exchange. In Proceedings of the 1999 European Wind Energy Conference (EWEC), Nice, France, 1-5 March 1999; pp. 379-382.

2. Roulston, M.S.; Kaplan, D.T.; Hardenberg, J.; Smith, L.A. Using Medium-Range Weather Forecasts to Improve the Value of Wind Energy Production. Renew. Energy 2003, 28, 585-602. [CrossRef]

3. Pinson, P.; Chevallier, C.; Kariniotakis, G.N. Trading Wind Generation From Short-Term Probabilistic Forecasts of Wind Power. IEEE Trans. Power Syst. 2007, 22, 1148-1156. [CrossRef]

4. Barthelmie, R.J.; Murray, F.; Pryor, S.C. The Economic Benefit of Short Term Forecasting for Wind Energy in the UK Electricity Market. Energy Policy 2008, 36, 1687-1696. [CrossRef]

5. Fabbri, A.; Gómez San Román, T.; Abbad, J.R.; Méndez Quezada, V. Assessment of the Cost Associated With Wind Generation Prediction Errors in a Liberalized Electricity Market. IEEE Trans. Power Syst. 2005, 20, 1440-1446. [CrossRef]

6. Usaoloa, J.; Ravelo, O.; González, G.; Soto, F.; Dávila, C.; Díaz-Guerra, B. Benefits for Wind Energy in Electricity Markets from Using Short Term Wind Power Prediction Tools; a Simulation Study. Wind Eng. 2004, 28, 119-128. [CrossRef]

7. Matevosyan, J.; Söder, L. Minimization of imbalance cost trading wind power on the short term power market. In Proceedings of the 2005 IEEE Russia PowerTech, St Petersburg, Russia, 27-30 June 2005; pp. 1-7. [CrossRef] 
8. Martin, H.; Otterson, S. German intraday electricity market analysis and modeling based on the limit order book. In Proceedings of the 15th International Conference on the European Energy Market (EEM), Łødź, Poland, 27-29 June 2018; pp. 1-6. [CrossRef]

9. Available online: https://webstore.iec.ch/publication/26603 (accessed on 10 June 2020).

10. Dupré, A.; Drobinski, P.; Alonzo, B.; Badosa, J.; Briard, C.; Plougonven, R. Sub-hourly Forecasting of Wind Speed and Wind Energy. Renew. Energy 2020, 145, 2373-2379. [CrossRef]

11. Schwarz, G. Estimating the Dimension of a Model. Ann. Stat. 1978, 6, 461-464. [CrossRef]

12. Bailer-Jones, C.A.L.; Gupta, R.; Singh, H.P. An Introduction to Artificial Neural Network. In Automated Data Analysis in Astronomy; Narosa Publishing House: New Delhi, India, 2001; pp. 51-68.

13. Brown, B.G.; Katz, R.W.; Murphy, A.H. Time Series Models to Simulate and Forecast Wind Speed and Wind Power. J. Appl. Meteorol. 1984, 23, 1184-1195. [CrossRef]

14. Féron, O.; Tankov, P.; Tinsi, L. Price formation and optimal trading in intraday electricitymarkets. arXiv 2020, arXiv:2009.04786, submitted.

(C) 2020 by the authors. Licensee MDPI, Basel, Switzerland. This article is an open access article distributed under the terms and conditions of the Creative Commons Attribution (CC BY) license (http:/ / creativecommons.org/licenses/by/4.0/). 